\section{Catatonia in autistic spectrum disorders}

\author{
LORNA WING and AMITTA SHAH
}

\section{Background The clinical pictures of autistic spectrum disorders include features described in catatonia.}

\begin{abstract}
Aims To examine the severe exacerbation of the catatonic features of autistic disorders in adolescence or early adult life, which occurs in some individuals.
\end{abstract}

Method A semi-structured interview schedule was used to collect information from parents or other care-givers concerning 506 referrals to a specialist clinic for autistic spectrum disorders. Individuals with severe exacerbation of catatonic features were compared with a same-age group of referrals without this type of deterioration in skills and behaviour.

Results Seventeen per cent of referrals aged 15 or over had severe exacerbation of catatonic features. They were significantly more likely than the comparison group to have had, before the onset of the change in behaviour, impaired language and passivity in social interaction.

Conclusions Catatonia is a later complication of autistic spectrum disorders, which adds considerably to the burden of caring. More research is needed to identify causes, neuropathology, and early signs of vulnerability.

Declaration of interest None.
Catatonia is a term used to refer to a cluster of behavioural features. In its extreme form, it is manifested as absence of speech (mutism), absence of movement (akinesia) and maintenance of imposed postures (catalepsy). Lesser degrees of these impairments, and various other abnormalities of posture, movement, speech and behaviour, are also considered to be catatonic phenomena (Bush et al, 1996; Joseph, 1992). Autistic spectrum disorders are characterised by a triad of impairments affecting the development of social interaction, communication and imagination. This triad is associated with a narrow, repetitive pattern of interests and activities and a range of other abnormalities of language, movement and behaviour (Wing \& Gould, 1979), similar to the lesser manifestations of catatonia (Leary \& Hill, 1996; Wing, 1996). Some individuals have a severe exacerbation of these features in adolescence or adult life (Realmuto \& August, 1991; Wing, 1996). The present study examines the frequency of this exacerbation among people with autistic disorders referred to a diagnostic centre, and compares the characteristics of referrals with and without this marked deterioration in behaviour.

\section{METHOD}

\section{Population studied}

During the period March 1991 to December 1997, 506 children and adults with autistic spectrum disorders were referred to the Elliot House Centre for Social and Communication Disorders, which is the National Autistic Society's tertiary referral centre and accepts referrals from anywhere in the UK or overseas. The majority $(94 \%)$ of these were seen at Elliot House for diagnostic assessment. The remainder were seen where they were currently living: in residential homes, hospitals or, in a few cases, their parents' homes.
The Elliot House team tends to see children and adults presenting complicated diagnostic problems. The fact that the staff members have a particular interest in catatonia has also become known and probably influences the pattern of referrals.

\section{Criteria for catatonia}

There are no generally accepted standardised criteria for diagnosing catatonia. In this study, a diagnosis of catatonia was given when exacerbation of certain features of behaviour occurred in sufficient degree to interfere with movement and everyday functions of self-care, education, occupation and leisure. The essential features were:

(a) increased slowness affecting movements and verbal responses;

(b) difficulty in initiating and completing actions;

(c) increased reliance on physical or verbal prompting by others; and

(d) increased passivity and apparent lack of motivation.

Other abnormalities of behaviour often associated were:

(e) reversal of day and night;

(f) Parkinsonian features: tremor, eyerolling, dystonia, odd stiff posture, freezing in postures, etc.;

(g) excitement and agitation; and

(h) increase in repetitive, ritualistic behaviour.

\section{Clinical assessment}

For those seen at Elliot House, information was collected from an appropriate informant, usually one or both parents, using the Diagnostic Interview for Social and Communication Disorders (DISCO; further details available from the first author upon request). This is a semi-structured interview that enables the interviewer to obtain, in a systematic fashion, details concerning the medical history and the pattern of development from birth of a wide range of skills and atypical behaviour. It contains a section on associated psychiatric disorders and another on catatonic phenomena.

When the assessments were carried out in other locations, the same procedures were adopted as far as possible. In some cases, the diagnosis of an autistic spectrum disorder had already been firmly established. For these individuals, the purpose 
of the consultation was to consider how to manage challenging behaviour, sometimes including difficulties due to catatonic features. Relevant diagnostic information was collected from case notes, supplemented by informants. For the 14 individuals $(2.8 \%)$ about whose early history no informant was available, as much information as possible was obtained from past case records. In all cases, the DISCO was used as the framework for recording details.

A study of interrater agreement has recently been completed for the DISCO, with the participation of parents of children who had not been seen at Elliot House. For over $80 \%$ of all the developmental and behavioural ratings made (515), kappa was equal to, or better than, 0.75 or, for the few ratings where kappa was not appropriate, agreement was $90 \%$ or above (further details available from the first author upon request).

\section{Diagnosis}

The autistic spectrum is similar to, but broader than, the category of pervasive developmental disorders in the tenth revision of the International Classification of Diseases (ICD-10) (World Health Organization, 1993). The subgroups represented among the individuals in the study were Asperger syndrome, childhood autism and atypical autism. The criteria used for Asperger syndrome were those suggested by Ehlers \& Gillberg (1993) because the ICD-10 criteria had been found to be unsatisfactory (Leekam et al, 2000). The ICD-10 criteria for childhood autism and atypical autism were used. When criteria for both autism and Asperger syndrome were present in one individual, the latter diagnosis was given. This is contrary to ICD-10 instructions but was more relevant to the needs of the individuals concerned.

\section{Social interaction}

One of the sections in the DISCO concerns social interaction. Individuals in the study could be assigned to one of three subgroups, based on the quality of their interactions with others. The three categories were 'aloof' (indifferent to social approaches, although physical contact might be enjoyed), 'passive' (accepting social approaches and following other's lead but not initiating any contact), and 'active but odd' (making active social approaches but in an inappropriate manner) (Wing $\&$ Gould, 1979; Wing, 1996). Clinical observation before the study began had suggested that individuals with autistic spectrum disorders who were passive in their social interactions were particularly vulnerable to the development of severe exacerbations of catatonic features. For the individuals with catatonia, the rating was based on information concerning behaviour before the catatonia began. For the comparison group, the rating was made for behaviour current at the time when they were seen by the Elliot House team.

\section{Psychological assessment}

Although associated cognitive deficits of any level of severity are very common, autistic spectrum disorders can occur in individuals of average or superior cognitive ability on formal intelligence tests (Rutter, 1970; Wing \& Gould, 1979; Wing, 1996). Assessments of cognitive skills were carried out, using standardised tests appropriate for age and ability to cooperate. The subjects were observed in structured and unstructured situations. Because of the difficulties of testing individuals with catatonia, for this group the estimates of cognitive ability were based on performance before the onset of catatonia, using information obtained from case records and interviews with parents or care-givers. For the comparison group, the estimate was based on the findings when seen and assessed by the Elliot House team.

\section{Cognitive ability}

On the results of assessments carried out as described above, individuals were classified into three groups: severe learning disability (IQ 0-49), mild learning disability (IQ 50 69) and borderline, average or high ability (IQ 70 and above). Because of the large discrepancies between different areas of skill, which are characteristic of autistic disorders, the estimates were approximations, but do give an indication of the overall level of function.

\section{Expressive language}

Expressive language was assessed on standardised measures where possible, or on history and observation when testing was not possible. As with other psychological assessments, estimates of expressive language in those with catatonia were based on information concerning language before the onset of the catatonia. For the comparison group, the estimates were based on assessments by the Elliot House team. Two subgroups were identified: those with no, impaired or deviant language (languageimpaired); and those with grammatical speech and an adequate or good vocabulary (language not impaired).

\section{Type of residence}

At the time when they were seen and assessed, individuals in the study were in four different types of residence: living independently; at home with parents; in a small residential home in the community; or in a hospital ward.

\section{Statistical analysis}

A one-way analysis of variance was used to compare ages. Otherwise, Pearson's $\chi^{2}$ tests were used.

\section{RESULTS}

\section{Prevalence among referrals}

A total of 30 individuals with autistic spectrum disorders (6\% of all referrals) met the above criteria for catatonia. Their ages when seen at Elliot House ranged from 15 to 50 years. Table 1 shows the numbers and percentages of these with catatonia among all referrals, by age group when seen. All of those with catatonia were aged 15 or above at referral. They represented $17 \%$ of all referrals in that age range.

A further eight individuals (five males (one with Down's syndrome) and three females, aged 10-36 years when seen) had occasionally had problems crossing thresholds and/or freezing during activity, but were not disabled enough to be included in the catatonic group. In two of these, the brief catatonic episodes had occurred

Table I Ages when seen at Elliot House

\begin{tabular}{lccc}
\hline \multirow{2}{*}{$\begin{array}{l}\text { Age group } \\
\text { (years) }\end{array}$} & Total seen & \multicolumn{2}{c}{ With catatonia } \\
\cline { 3 - 4 } & $n$ & $n$ & $(\%)$ \\
\hline $1-4$ & & - & $(-)$ \\
$5-9$ & 90 & - & $(-)$ \\
$10-14$ & 159 & - & $(-)$ \\
$15-19$ & 82 & 12 & $(17)$ \\
$20-24$ & 65 & 8 & $(17)$ \\
$25-29$ & 48 & 3 & $(16)$ \\
$30-34$ & 19 & 5 & $(25)$ \\
$35+$ & 20 & 2 & $(9)$ \\
Total & 23 & 30 & $(6)$ \\
\hline
\end{tabular}


only in early or middle childhood. In one, catatonic features were seen at school but not at home.

\section{Characteristics of the group with catatonia}

Age of onset

The ages of onset of the current episode of catatonia, obtained from the recollections of informants, are given in Table 2. For four individuals, the ages of onset could not be ascertained. For the rest, the majority started the current episode between 10 and 19 years of age. Five individuals had had brief episodes of slowness and freezing during childhood, before age 10 .

\section{Type of onset}

In 15 individuals, the onset was immediately preceded by a period of very disturbed, often aggressive, behaviour. Eight individuals developed obsessivecompulsive symptoms before they became catatonic. Six of these were among those who had shown disturbed, aggressive behaviour before the onset of catatonia.

\section{Possible precipitating factors}

Possible precipitating factors were suggested for 13 individuals. These included bereavement, pressure at school, lack of structure after leaving school, and lack of occupation. The individuals concerned did not communicate their feelings about these events. The suggestion of a connection with the onset of the catatonia was made by the parents or other care-givers.

\section{Course}

Information about any fluctuations in the catatonic state over time was obtained from parents or other carers and from available

Table 2 Ages of onset of catatonia

\begin{tabular}{lc}
\hline Age group (years) & $n$ \\
\hline $1-4$ & - \\
$5-9$ & - \\
$10-14$ & 7 \\
$15-19$ & 16 \\
$20-24$ & 2 \\
$25-29$ & 1 \\
Not known & 4 \\
Total & 30 \\
\hline
\end{tabular}

case notes. From the onset of catatonia up to the time they were seen at Elliot House, three individuals had experienced a slow but steady deterioration in mobility and practical skills. In 17, the course had been steady once the catatonia was established, while four had shown minor and six had shown major fluctuations in severity.

\section{Manifestations of catatonic behaviour}

The most common manifestations of catatonic behaviour seen in the group, each affecting seven or more individuals, are listed in Table 3. Most of the abnormalities of movement resulted in slowing or stopping activities, but episodes of excitement and sudden impulsive actions also occurred. Some could not stop actions once started. Incontinence resulted when the individual concerned did not initiate the movement needed to reach the toilet.

As shown in Table 3, 12 individuals showed bizarre behaviour that could not be classified under other headings. For example, two individuals would never use one arm and hand (the left in one case and the right in the other), although no physical reason could be found. One man walked the same route to the same destination each day in order to stand motionless, staring for 2 hours at a spot where a building used to be before it was pulled down. Others had occasional visual hallucinations or paranoid ideas that did not fit any particular diagnosis.

Table 3 Most frequent manifestations of catatonia

\begin{tabular}{lc}
\hline Catatonic manifestations & $\begin{array}{c}\text { Feature } \\
\text { present } \\
n\end{array}$ \\
& 30 \\
\hline Essential criteria (slowness, difficulty & \\
$\quad$ initiating movements, needs & \\
$\quad$ prompts, passive) & 27 \\
Odd gait & 19 \\
Odd, stiff postures & 17 \\
Freezing & 16 \\
Impulsive acts & 16 \\
Difficulty crossing lines & 12 \\
Bizarre/psychotic & 10 \\
Sleep problems & 10 \\
Incontinence & 7 \\
Cannot stop actions & 7 \\
Excited phases & \\
\hline
\end{tabular}

According to the accounts given by relatives or other carers, none had ever had the first-rank symptoms of schizophrenia. All showed abnormalities of speech, but these were indistinguishable from those found in autistic disorders. The quantity of speech was in all cases markedly reduced or absent when catatonia was present.

\section{Severity of the effect of catatonia on daily activities}

At the time of referral, the 30 individuals in the catatonic group varied in the degree to which the catatonia interfered with their participation in everyday activities, their mobility and their independence, as follows.

Twelve with the least severe symptoms were mobile but were very slow in carrying out all self-care activities, often freezing during an activity and needing prompting to begin moving again. They had difficulty crossing thresholds or demarcation lines, but were able to take part in the daily activities with much help from staff.

Fourteen were more severely affected. They were so slow, or so unable to cross thresholds, or so locked into one repetitive activity, that their daily programme was severely impoverished.

Four individuals were the most severely affected. Their lives were completely disrupted by their symptoms. One stayed in one room, rocking in a chair, and could not leave the house unless carried out, as stiff as a statue, completely covered by a blanket. One had to be half-lifted by two care-givers to enable him to cross any demarcation lines, including cracks in pavements. One sat immobile unless physically prompted, not even moving to empty her bladder. However, when taken out and started on a route, she would walk for miles without a pause until prompted to stop. The fourth was permanently confined to a wheelchair, apart from one occasion when his elderly father stumbled and nearly fell. Seeing this, the son leapt from his wheelchair, helped his father to sit down and then returned to immobility.

None of the above variables was significantly related to autistic spectrum subgroup, expressive language, level of ability or quality of social interaction.

\section{Comparison with a group without catatonia}

The comparison group comprised 115 individuals with autistic spectrum disorders 
whose age range (when they were seen at Elliot House) was the same as that of those with catatonia (15 years and above), and whose clinical details were entered into a computer file. Twenty-two individuals in the same age range were excluded because they were not in the computer file for administrative reasons, not due to any bias in their clinical pictures. The eight with mild or previous catatonia mentioned above were also excluded.

\section{Age when seen at Elliot House}

The age range of those with catatonia was 17-50 years (mean 24.6). For the comparison group it was 15-60 years (mean 25.1). There was no significant difference between the groups.

\section{Gender}

There was an expected excess of males in both groups, somewhat more marked among those with catatonia. The difference between groups was not significant (see Table 4).

\section{Diagnostic subgroup}

In the group studied, catatonia occurred in a smaller proportion of those with Asperger syndrome than of those with childhood autism or atypical autism, but the difference was not significant (see Table 4).

\section{Quality of social interaction}

Only $17 \%$ of the comparison group were passive when assessed, whereas half of those with catatonia were passive before the onset of the catatonic behaviour $\left(\chi^{2}=14.98\right.$, d.f. $\left.=2, P<0.001\right)$ (see Table 4).

\section{Level of cognitive ability}

In the group studied, catatonia was seen in a somewhat higher proportion of those with learning disabilities, but the difference between the groups was not significant (see Table 4).

\section{Expressive language}

The individuals with catatonia were more likely to be language-impaired than the comparison group $\left(\chi^{2}=6.95\right.$, d.f. $=1, P=0.008$ with continuity correction) (see Table 4).

\section{Type of residence}

More of the group with catatonia were currently in some form of residential care,

Table 4 Characteristics of the catatonia and comparison groups

\begin{tabular}{|c|c|c|c|c|c|}
\hline \multirow[t]{2}{*}{ Variable } & \multicolumn{2}{|c|}{ Catatonia group $(n=30)$} & \multicolumn{2}{|c|}{ Comparison group $(n=I 15)$} & \multirow[t]{2}{*}{$P$} \\
\hline & $n$ & (\%) & $n$ & (\%) & \\
\hline \multicolumn{6}{|l|}{ Gender } \\
\hline Male & 28 & $(93)$ & 91 & (79) & \multirow{2}{*}{ NS } \\
\hline Female & 2 & (7) & 24 & $(2 I)$ & \\
\hline \multicolumn{6}{|l|}{ Diagnostic subgroup } \\
\hline Autism & II & $(37)$ & 32 & $(28)$ & \multirow{3}{*}{ NS } \\
\hline Atypical autism & 5 & (17) & 8 & (7) & \\
\hline Asperger syndrome & 14 & $(47)$ & 75 & $(65)$ & \\
\hline \multicolumn{6}{|l|}{ Social interaction } \\
\hline Aloof & 5 & (17) & 18 & $(16)$ & \multirow{3}{*}{$<0.001$} \\
\hline Passive & 15 & $(50)$ & 19 & $(17)$ & \\
\hline Active/odd & 10 & (33) & 77 & (67) & \\
\hline \multicolumn{6}{|l|}{ Level of cognitive ability } \\
\hline Severe learning disability & 9 & $(30)$ & 22 & (19) & \multirow{3}{*}{ NS } \\
\hline Mild learning disability & 9 & $(30)$ & 19 & $(17)$ & \\
\hline Borderline/average & 12 & $(40)$ & 74 & $(64)$ & \\
\hline \multicolumn{6}{|l|}{ Expressive language } \\
\hline Impaired & 16 & $(43)$ & 30 & (26) & \multirow{2}{*}{0.008} \\
\hline Not impaired & 14 & $(57)$ & 85 & (74) & \\
\hline \multicolumn{6}{|l|}{ Residence } \\
\hline Parents' home & 9 & $(30)$ & 70 & $(6 I)$ & \multirow{4}{*}{$<0.001$} \\
\hline Own home & - & $(-)$ & 16 & $(14)$ & \\
\hline Care home & 12 & $(40)$ & 13 & (II) & \\
\hline Hospital & 9 & $(30)$ & 16 & $(14)$ & \\
\hline
\end{tabular}

including psychiatric hospitals $\left(\chi^{2}=23.27\right.$, d.f. $=3, P<0.001$ ) (see Table 4$)$.

\section{Epilepsy}

Four $(13 \%)$ of those with catatonia and $25(22 \%)$ in the comparison group had a history of one or more epileptic fits. The difference between the groups was not significant.

\section{DISCUSSION}

\section{Prevalence}

As previously noted, the number of individuals with catatonia, as defined above, among Elliot House referrals was probably unusually high. The proportion of individuals with this type of deterioration in skills and behaviour should not, without further investigation, be considered as typical of autistic disorders in general. It is also possible that the factors found to be significantly associated with catatonia can be explained by referral bias. Nevertheless, the comparisons between those with and those without catatonia remain valid.

\section{Factors involved in the development of catatonia}

Catatonia was seen more often in those who had impaired expressive language, and those who were passive in social interaction, before the onset of catatonia. Within the group of those who developed catatonia, however, the number of catatonic features and the degree to which the catatonia limited everyday activities had no significant relationship to expressive language ability or type of social interaction.

In the majority of individuals in this study, the onset of severe catatonia occurred in the years from 10 to 19 , although a few had also had brief episodes of freezing, or difficulty crossing thresholds, in childhood. Adolescence is associated with physical and psychological stresses. However, in more than half of the group studied, no particular precipitating cause could be identified, although they may have experienced stresses that were idiosyncratic to the individuals concerned but were not evident to the care-givers. Most adolescents with autistic disorders 
do not develop catatonia, although they too are likely to meet the same kinds of difficulties associated with growing up. It is possible that some individuals have an inherent vulnerability to developing catatonia, which becomes overt in response to stress.

\section{Autistic disorders, catatonia and related motor disorders}

The terms 'catatonia' and 'autistic spectrum disorder' refer to clusters of behavioural features. They can each be associated with a range of physical and psychological conditions. They are best regarded as effects of underlying causes and not as causal entities. They share the fuzziness inherent in concepts defined only by a mix of behavioural features, even when operational criteria have been standardised, as with the ICD-10 classification. Nevertheless, they are useful concepts in clinical practice. It is necessary to use appropriate methods of management and treatment of the overt behaviour when, as in the group described here, a treatable underlying cause cannot be identified.

Autistic conditions are developmental disorders present from birth or early in life. The concept of catatonia was developed in relation to behaviour observed in adults. However, there is a marked overlap of the behavioural features of the two disorders. For example, motor stereotypies, mannerisms, rituals, mutism, echolalia and negativism, among others, are described in catatonia (Joseph, 1992; Bush et al, 1996) as well as in autistic spectrum disorders (Rutter, 1978, 1985; Wing, 1996). This overlap in the clinical pictures, as well as the findings reported here, raises the question of the nature of the relationship between the two disorders.

In this context it is relevant to note that the manifestations of catatonia that were most common in the group described here overlap with those found in parkinsonism. Damasio \& Maurer (1978) discussed the similarities between the motor phenomena of autism and of parkinsonism. Rogers (1992) considered that a rigid division of motor disorders into 'catatonic' (psychiatric) and extrapyramidal (neurological) was not appropriate because of the high correlation between scores in the same individuals on the relevant scales. He concluded that there seems to be a continuously distributed array of disorders of movement, volition and behaviour, ranging from the relatively

\section{CLINICAL IMPLICATIONS}

Catatonia develops in adolescence in a small proportion of individuals with autistic spectrum disorders.

Recognition of catatonia in individuals with autistic spectrum disorders is necessary in order to institute appropriate management and care.

- The presence of an undiagnosed autistic spectrum disorder should be considered in any individual presenting with catatonia.

\section{LIMITATIONS}

- The prevalence rate of catatonia was based on referrals to a specialist clinic and is likely to be higher than that for a total population.

- The study was cross-sectional and does not provide information on future course and prognosis.

- Profiles based on all clinical features were not examined in the catatonic and comparison groups.

LORNA WING, FRCPsych, Centre for Social and Communication Disorders, Bromley, Kent; AMITTA SHAH, MSc, Leading Edge Psychology, Purley, Surrey

Correspondence: Dr Lorna Wing, Centre for Social and Communication Disorders, Elliot House, Bromley, Kent BR2 9HT

(First received I5 June 1999, final revision 5 October 1999, accepted 12 October 1999)

simple disorders of dyskinesia and parkinsonism to the complex disturbances of catatonia, all of which can be related to the extrapyramidal system. Lishman (1997) described the clinical manifestations of encephalitis lethargica, the condition that was pandemic towards the end of the First World War and the 1920s. Lishman noted that catatonic phenomena could occur, and he mentioned all the behavioural features listed in the present paper.

The tendency to passivity in social interaction seen in some individuals before the onset of catatonia is, perhaps, a precursor of the lack of ability to initiate voluntary movement, which is typical of catatonia and parkinsonism. However, the findings do not corroborate the view of Leary \& Hill (1996) that autism is a purely motor problem. The social and cognitive disabilities are as important as the motor aspects and cannot be explained away.

Other disorders affecting movement that can co-occur with autistic disorders include the pictures resembling obsessivecompulsive disorder (Rutter, 1985), Tourette's syndrome (Realmuto \& Main, 1982) and attention-deficit hyperactivity disorder (Gillberg, 1992; Wing, 1996). The relationship between all these conditions and autistic disorders suggests that they have some aspect of their neuropathology in common.

\section{Implications for care, treatment and research}

Severe catatonia adds considerably to the difficulties of caring for individuals with autistic spectrum disorders, as shown by the numbers with catatonia who were in hospital placements. Admission was the result and not the cause of the catatonia.

It is important for clinicians to be aware of the possibility of catatonia when investigating reasons for deterioration in skills and behaviour occurring in adolescents and adults with autistic spectrum disorders. Conversely, the possibility of an underlying 
autistic disorder should be considered if an individual presents with catatonia. Possible physical or psychological causes should be investigated, and treated if found. In the absence of a treatable cause, there is no known cure for catatonia, but appropriate care and environmental management can help to alleviate the problems for the individual concerned and for their care-givers (further details available from the first author upon request).

Subjects for future research include investigation of the neuropathology, identification of early signs of vulnerability to exacerbation of catatonic features, the role of environmental stress, and methods of management and treatment.

\section{REFERENCES}

Bush, G., Fink, M., Petrides, G., et al (1996) Catatonia I. Rating scale and standardised examination. Acta Psychiatrica Scandinavica, 93, 129-136.
Damasio, A. R. \& Maurer, R. G. (1978) A neurological model for childhood autism. Archives of Neurology, $\mathbf{3 5}$ 777-786.

Ehlers, S. \& Gillberg, C. (1993) The epidemiology of Asperger syndrome; a total population study. Journal of Child Psychology and Psychiatry, 34, 1327-1350.

Gillberg, C. (1992) The Emmanuel Miller Memoria Lecture 1991: Autism and autistic-like conditions: subclasses among disorders of empathy. Journal of Child Psychology and Psychiatry, 33, 813-842.

Joseph, A. B. (1992) Catatonia. In Movement Disorders in Neurology and Neuropsychiatry (eds A. B. Joseph \& R. R. Young), pp. 335-342. Oxford: Blackwell.

Leary, M. R. \& Hill, D. A. (1996) Moving on: autism and movement disturbance. Mental Retardation, 34 39-53.

Leekam, S., Libby, S., Wing, L., et al (2000) Comparison of ICD-10 and Gillberg's criteria for Asperger syndrome. Autism, 4, II-28.

Lishman, W. A. (1997) Organic Psychiatry: The Psychological Consequences of Cerebral Disorder (3rd edn), pp. 349-356. Oxford: Blackwell.

Realmuto, G. M. \& Main, B. (1982) Coincidence of Tourette's disorder and infantile autism. Journal of Autism and Developmental Disorders, 12, 367-372.
_ \& August, G. (199I) Catatonia in autistic disorder; a sign of co-morbidity or variable expression? Journal of Autism and Developmental Disorders, 21, 517-528.

Rogers, D. (1992) Motor Disorder in Psychiatry: Towards a Neurological Psychiatry. Chichester: Wiley.

Rutter, M. (1970) Autistic children: infancy to adulthood. Seminars in Psychiatry, 2, 435-450.

- (1978) Diagnosis and definition. In Autism: A Reappraisal of Concepts and Treatment (2nd edn) (eds M. Rutter \& E. Schopler), pp. I-25. New York: Plenum.

- (1985) Infantile autism and other pervasive developmental disorders. In Child and Adolescent Psychiatry: Modern Approaches (2nd edn) (eds M. Rutter \& I. Hersov), pp. 545-566. Oxford: Blackwell.

Wing, L. (1996) The Autistic Spectrum: A Guide for Parents and Professionals. London: Constable.

\& Gould, J. (1979) Severe impairments of socia interaction and associated abnormalities in children: epidemiology and classification. Journal of Autism and Childhood Schizophrenia, 9, II-29.

World Health Organization (1993) The ICD-10 Classification of Mental and Behavioural Disorders: Diagnostic Criteria for Research. Geneva: WHO. 